\title{
Pengaruh Atribut dan Kualitas Layanan Agrowisata Taman Edelweis terhadap Kepuasan dan Niat Berkunjung Kembali Wisatawan di Tengah Pandemi COVID-19
}

\author{
The Influence of Edelweis Park Agrotourism Attributes and Service Quality \\ on Tourist Satisfaction and Revisit Intention in The Middle of The COVID-19 \\ Pandemic
}

\author{
Ni Made Classia Sukendar*) \\ I Gde Pitana \\ I Ketut Surya Diarta
}

\begin{abstract}
Fakultas Pertanian, Universitas Udayana, Bali, Indonesia
\end{abstract}
Email: madeclassia@gmail.com ${ }^{*}$

\begin{abstract}
Edelweis Park Agrotourism is a leading agrotourism developed as tourism attraction in Karangasem Regency. While it is growing in popularity, there is limited knowledge on the influence of the attributes of the attraction and service quality on satisfaction and tourist revisit intention during the COVID-19 pandemic. This research aimed to analyze the influence of the (a) attributes of destination attraction on tourist's satisfaction; (b) attributes of destination attraction on tourist's revisit intention; (c) service quality on tourist's satisfaction; (d) service quality on tourist's revisit intention; and (e) tourist's satisfaction on tourist's revisit intention in the middle of the COVID-19 pandemic. Considering a number of limitations, quota-accidental sampling technique was employed, whereby 100 respondents were selected. Results showed that the (a) attributes of the attraction have a significant and positive effect on tourist's satisfaction; (b) attributes of attraction have a significant and positive effect on tourist's revisit intention; (c) service quality has a significant and positive effect on tourist's satisfaction; (d) service quality does not have a significant effect on tourist's revisit intention, (e) tourist satisfaction has a significant and positive effect on tourist's revisit intention, but the trust variable has a weak moderation variable on tourist's satisfaction and revisit intention. Therefore, it is suggested to maintain the attributes of destination attraction, to improve the quality of service, to pay attention to tourist satisfaction. Future researches are needed on questions that are not discussed here, such as the influence of destination image on tourist satisfaction and revisit intention.
\end{abstract}

Keywords: attributes, service, satisfaction, revisit intention

\begin{abstract}
ABSTRAK
Agrowisata Taman Edelweis merupakan agrowisata unggulan yang dikembangkan sebagai DTW di Kabupaten Karangasem. Meskipun popularitasnya semakin meningkat, pengetahuan mengenai pengaruh atribut DTW dan kualitas layanan terhadap kepuasan dan niat berkunjung kembali wisatawatan selama pandemi COVID-19 masih terbatas.
\end{abstract}


Tujuan penelitian ini adalah untuk (a) menganalisis pengaruh atribut DTW agrowisata terhadap kepuasan pengunjung; (b) menganalisis pengaruh atribut DTW agrowisata terhadap niat kunjungan kembali; (c) menganalisis pengaruh kualitas pelayanan agrowisata terhadap kepuasan pengunjung; (d) menganalisis pengaruh kualitas pelayanan agrowisata terhadap niat kunjungan kembali; (e) menganalisis kepuasan pengunjung agrowisata terhadap niat kunjungan kembali wisatawan di tengah pandemi COVID-19. Mengingat sejumlah keterbatasan, teknik pengambilan sampel yang digunakan yaitu accidental sampling, dengan pemilihan 100 responden. Hasil penelitian menunjukkan bahwa (a) atribut DTW agrowisata berpengaruh positif dan signifikan terhadap kepuasan pengunjung; (b) atribut DTW agrowisata berpengaruh positif dan signifikan terhadap niat berkunjung kembali; (c) kualitas pelayanan agrowisata berpengaruh positif dan signifikan terhadap kepuasan pengunjung; (d) kualitas pelayanan tidak berpengaruh signifikan terhadap niat berkunjung kembali wisatawan, (e) kepuasan pengunjung berpengaruh positif dan signifikan terhadap variabel niat berkunjung kembali, namun variabel kepercayaan merupakan variabel moderasi yang bersifat lemah terhadap variabel kepuasan pengunjung dan niat berkunjung kembali. Dengan demikian disarankan agar mempertahankan atribut DTW, meningkatkan kualitas pelayanan, memberikan perhatian kepada kepuasan wisatawan. Melakukan penelitian lebih lanjut seperti menganalisis pengaruh citra destinasi terhadap kepuasan dan niat berkunjung kembali wisatawan.

Kata kunci: atribut, layanan, kepuasan, niat berkunjung

\section{PENDAHULUAN}

\section{Latar Belakang}

Prihadi (2020) menyatakan bahwa tren wisata alam merupakan tren wisata masa depan di era new normal. Salah satu strategi untuk memadupadankan pertanian dengan pariwisata adalah dengan mengembangan pariwisata berbasis pertanian atau yang secara umum disebut sebagai agrowisata atau agriwisata (Pitana dan Sarjana, 2020). Agrowisata Taman Edelweis merupakan agrowisata unggulan yang dikembangkan sebagai daya tarik wisata (DTW) di Kabupaten Karangasem. Agrowisata ini memiliki potensi besar sebagai DTW berbasis pertanian yang memiliki keunggulan pemandangan tanaman edelweis (padang kasna), pemandangan Gunung Agung, suasana yang sejuk, serta adanya spot-spot foto yang trendi. Kusyanda (2019) menyatakan bahwa atribut destinasi pariwisata dan kualitas pelayanan yang mempengaruhi kepuasan wisatawan dan niat berkunjung kembali merupakan satu kesatuan yang saling mempengaruhi dan dipengaruhi. Berdasarkan potensi yang dimiliki agrowisata Taman Edelweis, untuk saat ini belum diketahui dan belum ada penelitian yang membahas mengenai pengaruh atribut DTW dan kualitas layanan terhadap kepuasan dan niat berkunjung kembali wisatawan, terlebih di masa pandemi COVID-19. Oleh karena itu, penelitian ini menjadi penting dilakukan guna memberikan gambaran spesifik mengenai hal tersebut.

Atribut adalah karakteristik atau kualitas yang mencirikan sesuatu yang dalam hal ini merupakan identitas dari sesuatu (Herman, 2018). Atribut DTW yang menjadi perhatian di agrowisata ini terletak pada atraksi, fasilitas, aksesibilitas dan hospitality. Fenomena pada atraksi menurut Sueca (2020) yaitu pihaknya sedang merencanakan dan terus 
berinovasi untuk menambah atraksi, sehingga mampu menahan pengunjung untuk beraktivitas lebih lama. Fasilitas parkir menjadi kendala pada agrowisata ini karena hanya mampu menampung delapan mobil dan 20 sepeda motor (Nantra, 2018). Kurang baiknya aksesibilitas menuju lokasi karena lokasi yang sulit dijangkau pun merupakan tantangan yang dihadapi agrowisata Taman Edelweis (Pitana dan Sarjana, 2020). Beberapa jalan yang rusak dan berlubang, serta akses jalan yang kurang lebar juga menjadi kendala. Hospitality menjadi hal yang penting karena apabila wisatawan sudah merasa nyaman, maka akan memunculkan niat berkunjung kembali. Diarta dan Sarjana (2020) menyatakan kualitas layanan dimaknai sebagai sikap dan hubungan yang dihasilkan dari perbandingan antara harapan dan kinerja. Konsep kualitas layanan oleh Parasuraman et al. (1985, dalam Diarta dan Sarjana, 2020) yaitu tangible, reliability, responsiveness, assurance, dan emphaty. Fenomena pada assurance yaitu kurangnya penggunaan bahasa asing antara pengelola dengan pengunjung, serta pengetahuan SDM lokal yang masih terbatas. Adanya struktur kayu pada sarana dan prasarana yang dianggap kurang aman, beberapa paving yang lepas, perlunya pemilahan sampah botol, penambahan tong sampah dan toilet publik merupakan fenomena yang terjadi pada tangible.

Schiffman, et al. (2014, dalam Jannah, 2020) menyatakan kepuasan pengunjung dapat dicapai apabila kebutuhan atau motivasi pengunjung dapat terpenuhi ketika telah memutuskan untuk berkunjung ke suatu destinasi wisata tertentu. Lima elemen kepuasan konsumen menurut Wilkie (1994, dalam Kusyanda, 2019) yaitu expectation, performance, comparison, confirmation dan disconfirmation. Fenomena pada performance yaitu beberapa tanaman kurang mendapatkan perawatan serta beberapa tanaman padang kasna yang rebah. Perbedaan ekspektasi dengan kenyataan terjadi pada pengunjung yang datang untuk melihat tanaman edelweis yang mereka ketahui, tetapi sesampainya di lokasi pengunjung hanya menemukan tanaman padang kasna. Apabila pengunjung merasa puas, maka pengunjung akan berkunjung kembali. Adanya kunjungan kembali ke agrowisata Taman Edelweis, diharapkan agrowisata ini tetap berkelanjutan sehingga mampu terus membangun potensi yang ada serta dapat dirasakan oleh generasi selanjutnya. Menurut data dari Dinas Pariwisata Provinsi Bali (2020), Taman Edelweis merupakan DTW di Kabupaten Karangasem yang sudah tersertifikasi penerapan protokol kesehatan. Sertifikasi ini dianggap mampu meningkatkan kepercayaan pengunjung untuk berkunjung di tengah pandemi COVID19. Adapun tiga pembentuk faktor kepercayaan menurut Mayer et al. (1995, dalam Subekti, 2020) yaitu ability, benevolence dan integrity.

\section{Tujuan Penelitian}

Tujuan dari penelitian ini adalah untuk menganalisis pengaruh atribut DTW agrowisata Taman Edelweis terhadap kepuasan pengunjung di tengah pandemi COVID-19, menganalisis pengaruh atribut DTW agrowisata Taman Edelweis terhadap niat berkunjung kembali wisatawan di tengah pandemi COVID-19, menganalisis pengaruh kualitas pelayanan agrowisata Taman Edelweis terhadap kepuasan pengunjung di tengah pandemi COVID-19, menganalisis pengaruh kualitas pelayanan agrowisata Taman Edelweis terhadap niat berkunjung kembali wisatawan di tengah pandemi COVID-19, menganalisis pengaruh kepuasan pengunjung agrowisata Taman Edelweis terhadap niat berkunjung kembali di tengah pandemi COVID-19. 


\section{METODELOGI PENELITIAN}

Penelitian ini dilakukan di Agrowisata Taman Edelweis, Banjar Dinas Temukus, Desa Besakih, Kecamatan Rendang, Kabupaten Karangasem, dari bulan September 2020 sampai Mei 2021. Pemilihan lokasi dilakukan secara sengaja dengan pertimbangan; a) memiliki tanaman yang unik (padang kasna), b) penelitian di agrowisata ini masih tergolong sedikit, c) salah satu DTW di Kabupaten Karangasem, d) buka secara new normal mulai 9 Juli 2020, e) mengantongi sertifikat penerapan protokol kesehatan. Pendekatan yang digunakan yaitu kuantitatif dengan analisis SEM-PLS (Structural Equation Modeling - Partial Least Square) dengan software WarpPLS versi 6.0. Populasi yang digunakan berdasarkan data kunjungan di tengah pandemi COVID-19 dengan rata-rata populasi per bulan yaitu 8.537 wisatawan lokal dan nusantara. Penentuan sampel dengan rumus teknik Slovin, diperoleh ukuran sampel (n) sebanyak 100 responden. Hal ini diperkuat bahwa metode sampling SEM-PLS diatur bahwa jumlah sampel yang direkomendasikan 30 sampai 100 responden (Ghozali, 2014). Teknik pengambilan sampel yang digunakan yaitu nonprobability sampling dengan accidental sampling yang dipilih secara disproportionate stratified random sampling. Penelitian ini menggunakan $30 \%$ asal luar Bali dan $70 \%$ asal Bali. Jenis data yang digunakan yaitu kuantitatif dan kualitatif.

Sumber data yang digunakan yaitu data primer dan sekunder. Metode pengumpulan data yang digunakan yaitu dengan metode survey, kuesioner, wawancara, dan studi pustaka. Jenis variabel yang digunakan yaitu variabel eksogen (atribut DTW dan kualitas layanan ), endogen (kepuasan pengunjung dan niat kunjungan kembali), serta moderasi (trust). Pengukuran variabel penelitian melalui uji validitas dan reliabilitas. Penelitian ini menggunakan kuesioner sebagai instrumen penelitian dengan menggunakan skala likert. Menurut Sarwono (2012, dalam Kusyanda, 2019), terdapat dua jenis validitas yaitu konvergen dan deskriminan. Data yang telah dianalisis kemudian menghasilkan model persamaan struktural yang dievaluasi baik dari outer model (validitas, reliabilitas), dan inner model $\left(\mathrm{R}^{2}, \mathrm{~F}^{2}\right.$, Dirrect, Indirect dan Total Effect serta GoF). Gambar 1 merupakan model struktural berdasarkan variabel laten dan reflektifnya. 


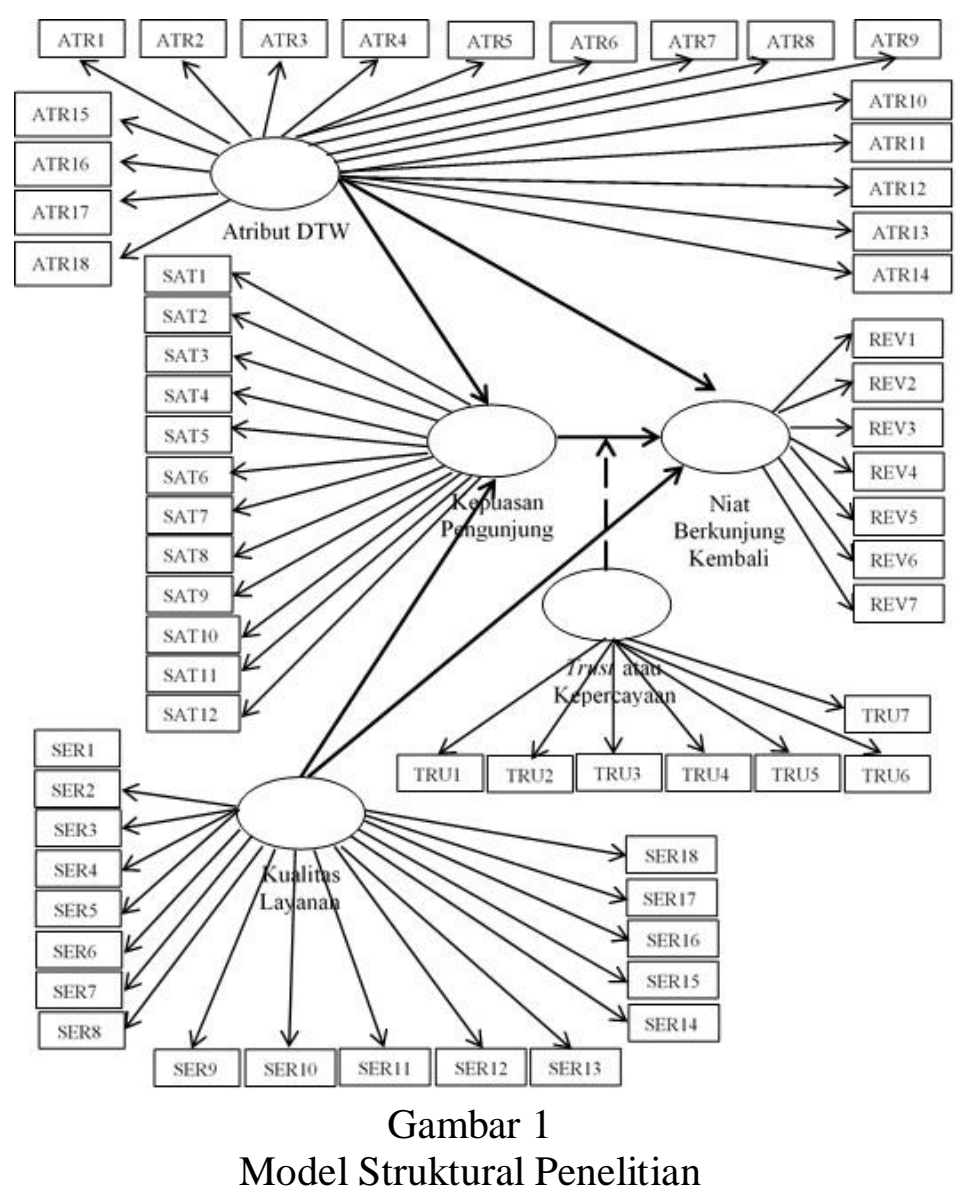

\section{HASIL DAN PEMBAHASAN}

\section{Tanggapan Responden terhadap Variabel Penelitian}

Distribusi frekuensi seluruh variabel penelitian dari masing-masing indikator berdasarkan 100 responden, didapatkan $47 \%$ responden setuju (skala 4), 30\% sangat setuju (skala 5). Dapat dikatakan tanggapan responden dalam penelitian ini didominasi oleh "setuju" dan "sangat setuju" dari lima variabel dan masing-masing indikator. Apabila digabungkan, maka $77 \%$ responden memberikan tanggapan positif. Kemudian, $15 \%$ responden netral (skala 3), tidak setuju 7\% (skala 2), dan sangat tidak setuju $1 \%$ (skala 1). Apabila digabungkan, terdapat $8 \%$ responden memberikan tanggapan negatif. Maka dari itu, terdapat beberapa hal yang perlu diperhatikan oleh pengelola untuk menjadikan atribut DTW dan kualitas pelayanan untuk menciptakan kepuasan pengunjung dan niat berkunjung kembali di masa pandemi COVID-19.

\section{Hasil Analisis Uji Validitas dan Uji Reliabilitas}

Kuesioner penelitian telah diuji validitas dan reliabilitasnya dan menunjukkan bahwa instrumen yang digunakan valid dan reliabel seperti yang ditunjukkan pada Tabel 1, Tabel 2, dan Tabel 3. 
Tabel 1. Hasil Pengujian Validitas Konvergen Variabel Penelitian




Tabel 2. Hasil Pengujian Validitas Diskriminan Variabel Penelitian

\begin{tabular}{lcc}
\hline \multicolumn{1}{c}{ Variabel } & AVE & Akar AVE \\
\hline Atribut DTW (ATR) & 0,645 & 0,803 \\
Kualitas Layanan (SER) & 0,662 & 0,813 \\
Kepuasan Pengunjung (SAT) & 0,762 & 0,873 \\
Niat Berkunjung Kembali (REV) & 0,753 & 0,868 \\
Trust atau Kepercayaan (TRU) & 0,724 & 0,851 \\
Trust Memoderasi Kepuasan Pengunjung (TRU * SAT) & 0,840 & 0,916 \\
\hline
\end{tabular}

Sumber: Data Hasil Penelitian (Data diolah), 2021

Tabel 3. Hasil Pengujian Reliabilitas Variabel Penelitian

\begin{tabular}{lcc}
\multicolumn{1}{c}{ Variabel } & $\begin{array}{c}\text { Cronbach's } \\
\text { Alpha }\end{array}$ & Composite Reliability \\
\hline Atribut DTW (ATR) & 0,949 & 0,956 \\
Kualitas Layanan (SER) & 0,969 & 0,972 \\
Kepuasan Pengunjung (SAT) & 0,971 & 0,974 \\
Niat Berkunjung Kembali (REV) & 0,945 & 0,955 \\
Trust atau Kepercayaan (TRU) & 0,936 & 0,948 \\
Trust Memoderasi Kepuasan Pengunjung (TRU * SAT) & 0,998 & 0,998 \\
\hline
\end{tabular}

Sumber: Data Hasil Penelitian (Data diolah), 2021

\section{Kelayakan Model Persamaan Struktural}

Tabel 4 memperlihatkan koefisien determinasi ( $R$-Squared) sebesar 0,605 menunjukkan variabel kepuasan pengunjung terhadap agrowisata Taman Edelweis sebesar 60,5\% dapat dijelaskan oleh variabel atribut DTW dan kualitas layanan agrowisata Taman Edelweis yang tergolong moderat (Ghozali, 2014). Koefisien determinasi sebesar 0,655 menunjukkan variabel niat berkunjung kembali pengunjung terhadap agrowisata Taman Edelweis sebesar 65,5\% dapat dijelaskan oleh variabel atribut DTW, kualitas layanan, dan kepuasan pengunjung agrowisata Taman Edelweis yang tergolong moderat (Ghozali, 2014). Nilai $Q$-Squared sebesar 0,606 dan 0,657>0 yang berarti estimasi model menunjukkan validitas prediktif yang baik. Nilai Full Colinearity VIF semua variabel dalam model pengukuran < 3,3 yang berarti model bebas dari masalah kolinearitas (Sholihin dan Ratmono, 2013).

Tabel 4. Goodness of Fit Persamaan Struktural

\begin{tabular}{|c|c|c|c|c|c|c|}
\hline \multirow[b]{2}{*}{$\begin{array}{c}\text { Kriteria } \\
\text { Goodness of Fit }\end{array}$} & \multicolumn{6}{|c|}{ Variabel } \\
\hline & Atribut DTW & $\begin{array}{l}\text { Kualitas } \\
\text { Layanan }\end{array}$ & $\begin{array}{l}\text { Kepuasan } \\
\text { Pengunjung }\end{array}$ & $\begin{array}{c}\text { Niat } \\
\text { Berkunjung } \\
\text { Kembali }\end{array}$ & $\begin{array}{c}\text { Keperca } \\
\text { yaan }\end{array}$ & $\begin{array}{l}\text { Kepercayaan } \\
\text { Memoderasi } \\
\text { Kepuasan } \\
\text { Pengunjung }\end{array}$ \\
\hline$R$-Squared & - & - & 0,605 & 0,655 & - & - \\
\hline Composite Reliability & 0,956 & 0,972 & 0,974 & 0,955 & 0,948 & 0,998 \\
\hline Cronbach's Alpha & 0.949 & 0,969 & 0,971 & 0,945 & 0,936 & 0,998 \\
\hline Average Variance & 0,645 & 0,662 & 0,762 & 0,753 & 0,724 & 0,840 \\
\hline Extracted & & & & & & \\
\hline Full Colinearity VIF & 2,648 & 3,161 & 3,149 & 3,270 & 1,788 & 1,309 \\
\hline$Q$-Squared & - & - & 0,606 & 0,657 & - & - \\
\hline
\end{tabular}

Sumber: Data Hasil Penelitian (Data diolah), 2021 
Tabel 5. Pengaruh Langsung (Dirrect Effect) Variabel Penelitian

\begin{tabular}{clcccc}
\hline Hip. & \multicolumn{1}{c}{ Var. Eksogenus $>$ Endogenus } & $\begin{array}{c}\text { Path } \\
\text { Coefficient }\end{array}$ & $\begin{array}{c}\text { Effect } \\
\text { Size }\end{array}$ & $\begin{array}{c}\text { Standar } \\
\text { Error }\end{array}$ & P Value \\
\hline H1 & Atribut DTW (X1) > Kepuasan Pengunjung (Y) & 0,431 & 0,295 & 0,173 & $<0,01$ \\
& & & & & $(* * *)$ \\
H2 & Atribut DTW $(\mathrm{X} 1)>$ Niat Berkunjung Kembali (Z) & 0,284 & 0,191 & 0,148 & 0,029 \\
H3 & Kualitas Layanan (X2) > Kepuasan Pengunjung (Y) & 0,448 & 0,310 & 0,186 & $<0,01$ \\
& & & & $(* * *)$ \\
H4 & Kualitas Layanan (X2) $>$ Niat Berkunjung Kembali (Z) & 0,220 & 0,149 & 0,211 & 0,15 \\
H5 & Kepuasan Pengunjung (Y) > Niat Berkunjung Kembali (Z) & 0,433 & 0,328 & 0,211 & 0,021 \\
\hline
\end{tabular}

Sumber: Data Hasil Penelitian di Lapangan (Diolah), 2021

Tabel 6. Pengaruh Tidak Langsung (Indirect Effect) dari Hubungan Antar Variabel

\begin{tabular}{clcccc}
\hline Hip. & \multicolumn{1}{c}{ Var. Eksogenus > Endogenus } & $\begin{array}{c}\text { Path } \\
\text { Coefficient }\end{array}$ & $\begin{array}{c}\text { Effect } \\
\text { Size }\end{array}$ & $\begin{array}{c}\text { Standar } \\
\text { Error }\end{array}$ & P Value \\
\hline H6 & $\begin{array}{l}\text { Kepuasan Pengunjung (Y) > Trust } \text { atau Kepercayaan (M) } \\
\text { > Niat Berkunjung Kembali (Z) }\end{array}$ & 0,080 & 0,013 & 0,095 & 0,199 \\
H7 & $\begin{array}{l}\text { Atribut DTW (X1) > Kepuasan Pengunjung (Y) > Niat } \\
\text { Berkunjung Kembali (Z) }\end{array}$ & 0,187 & 0,126 & 0,103 & 0,036 \\
H8 & $\begin{array}{l}\text { Kualitas Layanan (X2) > Kepuasan Pengunjung (Y) > } \\
\text { Niat Berkunjung Kembali (Z) }\end{array}$ & 0,194 & 0,131 & 0,120 & 0,054 \\
\hline
\end{tabular}

Sumber: Data Hasil Penelitian di Lapangan (Data diolah), 2021

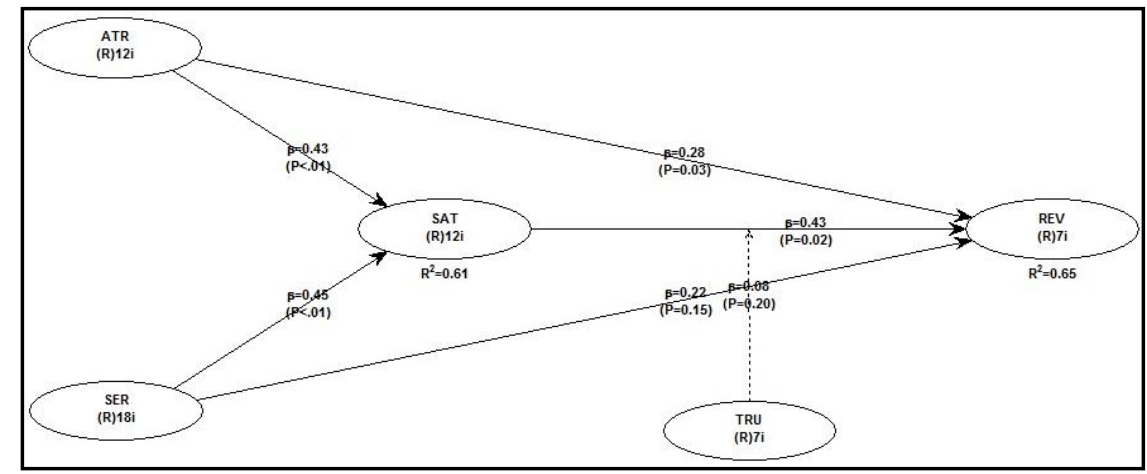

Gambar 2. Model Persamaan Struktural Penelitian

Sumber: Data Hasil Penelitian di Lapangan (Diolah), 2021

\section{Pengaruh Variabel Atribut Daya Tarik Wisata Agrowisata Taman Edelweis terhadap Variabel Kepuasan Pengunjung di Tengah Pandemi COVID-19}

Gambar 2 dan Tabel 5 menunjukkan output model persamaan struktural variabel atribut DTW berpengaruh signifikan terhadap kepuasan pengunjung dengan nilai path coefficient $0,431(\mathrm{p}<0,01)$, maka $\mathrm{H}_{0}$ ditolak, yang berarti $\mathrm{H}_{1}$ diterima. Dua belas dari 18 indikator variabel atribut DTW berpengaruh positif dan signifikan. Indikator berdasarkan nilai outer loading terbesar yaitu ATR18 atau X1.18 yaitu keramahtamahan petani di sekitar DTW yang patuh dengan protokol kesehatan $(0,906)$. Hospitality atau keramahtamahan merupakan bagian penting dalam suatu DTW. Keramahtamahan petani di suatu DTW tentu menyebabkan pengunjung merasa puas atas pengelolaan sebuah DTW. Indikator yang terkecil adalah ATR7 atau X1.7 yaitu ketersediaan toilet yang dilengkapi tempat cuci tangan maupun handsanitizer $(0,699)$. Indikator ini menjadi indikator terkecil dikarenakan kurang tersedianya toilet di sekitaran area agrowisata Taman Edelweis, karena toilet tersebut hanya tersedia di bagian depan taman, sehingga apabila pegunjung ingin ke toilet, pengunjung harus putar balik 
kebagian depan taman. Urutan indikator ditengah-tengah adalah ATR1 atau X1.1 yaitu lanskap agrowisata Taman Edelweis yang indah (instagramable) $(0,825)$, dan ATR8 atau X1.8 yaitu tempat istirahat (gazebo) yang dilengkapi handsanitizer dan pengaturan jarak tempat duduk $(0,788)$. Hal yang unik disini adalah indikator ATR18 (keramahtamahan petani) lebih besar dibandingkan indikator ATR16 atau X1.16 (keramahtamahan petugas). Pengunjung merasa puas dengan keramahtamahan petani yang sedang bercocok tanam tetap ramah ketika ada pengunjung yang datang. Oleh karena itu, pengelola sebaiknya tetap mempertahankan atribut DTW, kelestarian lanskap, aktivitas petani, keramahtamahan, agar membangkitkan minat kunjungan. Peran pemerintah yaitu dengan perbaikan jalan menuju agrowisata, mengingat banyak jalan rusak dan berlubang.

\section{Pengaruh Variabel Atribut Daya Tarik Wisata Agrowisata Taman Edelweis terhadap Variabel Niat Berkujung Kembali Wisatawan di Tengah Pandemi COVID-19}

Variabel atribut DTW berpengaruh signifikan terhadap variabel niat berkunjung kembali wisatawan dengan nilai path coefficient $0,284(\mathrm{p}=0,029)$, maka $\mathrm{H}_{0}$ ditolak, yang berarti $\mathrm{H}_{1}$ diterima. Jika dilihat dari indikator variabel atribut DTW yang dijelaskan sebelumnya, maka yang paling berpengaruh adalah ATR18 atau X1.18. Niat berkunjung kembali sangat ditentukan oleh keramahtamahan penduduk sekitar yang berarti pengujung merasakan pengalaman baik yang didapatkan ketika berkunjung ke suatu DTW. Pengelola sebaiknya mempertahankan kualitas keramahtamahan agar menghindari keputusan wisatawan untuk tidak lagi mengunjungi agrowisata ini. Indikator yang terkecil adalah ATR7 atau X1.7. Adanya toilet tentu menunjang aktivitas wisatawan, sehingga hal tersebut akan mempegaruhi niat berkunjung kembali. Urutan indikator ditengah-tengah adalah ATR1 atau X1.1 dan ATR8 atau X1.8. Niat kunjungan kembali wisatawan juga dipengaruhi dari lanskap agrowisata yang instagramable serta adanya gazebo yang dilengkapi handsanitizer dan pengaturan jarak tempat duduk.

\section{Pengaruh Variabel Kualitas Pelayanan Agrowisata Taman Edelweis terhadap Variabel Kepuasan Pengunjung di Tengah Pandemi COVID-19}

Variabel kualitas layanan berpengaruh signifikan terhadap kepuasan pengunjung dengan nilai path coefficient $0,448(\mathrm{p}<0,01)$, maka $\mathrm{H}_{0}$ ditolak, yang berarti $\mathrm{H}_{1}$ diterima. Delapan belas indikator yang diajukan berpengaruh positif dan signifikan. Indikator dengan nilai outer loading terbesar adalah SER18 atau X2.18 yaitu manajemen pengelola yang memperhatikan kesehatan pengunjung di area DTW $(0,883)$. Pengunjung akan merasa puas apabila mendapatkan layanan yang baik dari suatu DTW. Layanan yang baik ditunjukkan oleh sikap manajemen pengelola yang memperhatikan pengunjung di area DTW seperti adanya pengecekan suhu badan kepada wisatawan dengan termogun sebelum memasuki area DTW serta penyediaan tempat cuci tangan selama di masa pandemi. Indikator yang terendah adalah SER5 atau X2.5 yaitu penyediaan ruang khusus untuk wisatawan yang suhu badannya diatas $37,5^{\circ} \mathrm{C}(0,652)$. Hal ini terjadi karena pengunjung tidak mengetahui ruangan tersebut, karena ruangan tersebut memang sudah tidak berfungsi secara optimal saat penelitian karena selama ini tidak ada pengunjung yang suhu badannya melebihi kapasitas tersebut. Apabila ada, maka langkah yang diambil yaitu pengunjung tidak diperbolehkan masuk ke area taman. Indikator dengan urutan ditengah-tengah adalah SER1 atau X2.1 yaitu kerapihan 
penampilan karyawan yang sesuai dengan protokol kesehatan dengan menggunakan masker atau faceshield $(0,839)$, dan SER6 atau X2.6 menempati janji kepada wisatawan sesuai dengan kenyataan di lapangan $(0,826)$. Hal yang unik adalah indikator SER15, SER16, SER17, SER14, SER13 menguraikan adanya komunikasi yang baik antara staff, pengelola dengan pengunjung. Keramahtamahan tentu mempengaruhi kepuasan pengunjung. Oleh karena itu, meskipun tingkat persepsi pengunjung puas terhadap layanan yang diberikan, hal ini tidak akan bertahan apabila layanan tidak dipertahankan kualitasnya sehingga menyebabkan agrowisata ini ditinggalkan pengunjung.

\section{Pengaruh Variabel Kualitas Pelayanan Agrowisata Taman Edelweis Terhadap Variabel Niat Berkunjung Kembali Wisatawan di Tengah Pandemi COVID-19}

Variabel kualitas layanan tidak berpengaruh signifikan terhadap niat berkunjung kembali wisatawan dengan nilai path coefficient $0,220(\mathrm{p}=0,15)$, maka $\mathrm{H}_{0}$ diterima, yang berarti $\mathrm{H}_{1}$ ditolak. Seperti yang diuraikan sebelumnya, indikator kualitas layanan dengan nilai outer loading tertinggi adalah SER18 atau X2.18, sedangkan yang terendah adalah SER5 atau X2.5. Indikator dengan nilai outer loading urutan ditengah-tengah adalah SER1 atau X2.1, dan SER6 atau X2.6. Agrowisata Taman Edelweis merupakan agrowisata yang dibuka di Tahun 2018, sehingga saat ini masih dalam tahap euforia. Pengunjung masih ingin mengetahui daya tarik yang terdapat di agrowisata ini, sehingga kualitas layanan masih belum menjadi fokus, mengingat juga adanya penerapan protokol kesehatan, serta perlunya jaga jarak menyebabkan standar kualitas layanan menurun. Oleh karena itu, dapat disimpulkan bahwa variabel kualitas layanan hanya sebagai pelengkap dari atribut DTW untuk menimbulkan niat berkunjung kembali wisatawan ke agrowisata Taman Edelweis ditengah masa pandemi COVID-19.

\section{Pengaruh Variabel Kepuasan Pengunjung Agrowisata Taman Edelweis terhadap Variabel Niat Berkunjung Kembali Wisatawan di Tengah Pandemi COVID-19}

Variabel kepuasan pengunjung berpengaruh signifikan terhadap variabel niat berkunjung kembali wisatawan dengan nilai path coefficient $0,433(\mathrm{p}=0,021)$, maka $\mathrm{H}_{0}$ ditolak, yang berarti $\mathrm{H}_{1}$ diterima. Dua belas indikator yang diajukan signifikan dan berpengaruh positif. Indikator dengan nilai outer loading terbesar adalah SAT2 atau Y2 yaitu wisatawan merasa puas dengan fasilitas DTW yang sudah menerapkan protokol kesehatan $(0,926)$, sedangkan yang terkecil adalah SAT4 atau Y4 yaitu wisatawan merasa puas dengan aksesibilitas menuju DTW (0,675). Indikator dengan urutan ditengah-tengah adalah SAT3 atau Y3 yaitu wisatawan merasa puas dengan keramahtamahan pengelola yang patuh protokol kesehatan $(0,887)$, serta SAT7 atau Y7 yaitu wisatawan merasa puas terhadap kerapihan dan kebersihan di DTW yang sesuai dengan protokol kesehatan (0,086). Dapat disimpulkan indikator fasilitas DTW mampu memberikan kepuasan pengunjung sehingga memunculkan niat berkunjung kembali. Namun, pemerintah memiliki peranan penting dalam mendukung dengan memperhatikan aksesibiltas menuju DTW karena rusak, agar mampu menimbulkan niat pengunjung untuk berkunjung kembali. 


\section{Pengaruh Variabel Kepuasan Pengunjung Agrowisata Taman Edelweis terhadap Niat Berkunjung Kembali Wisatawan di Tengah Pandemi COVID-19 dengan Trust atau Kepercayaan sebagai Variabel Moderasi}

Variabel kepuasan pengunjung tidak berpengaruh signifikan terhadap niat berkunjung kembali wisatawan melalui variabel trust atau kepercayaan dengan nilai path coefficient $0,080(\mathrm{p}=0,199)$, maka $\mathrm{H}_{0}$ diterima, yang berarti $\mathrm{H}_{1}$ ditolak. Variabel trust dapat mengubah variabel kepuasan pengunjung terhadap niat berkunjung kembali dari awalnya signifikan menjadi tidak signifikan, maka variabel trust dapat dihitung pengaruhnya sebagai variabel moderasi dengan nilai VAF (Variance Accounted For). Berdasarkan perhitungan tersebut, didapatkan nilai VAF sebesar 15,6\% (<20\%) yang tergolong lemah. Oleh karena itu, variabel trust merupakan variabel moderasi yang lemah. Data tersebut menunjukkan bahwa walaupun ada pandemi, niat berkunjung kembali wisatawan tetap besar sepanjang syarat protokol kesehatan terpenuhi. Oleh karena itu dapat disimpulkan variabel kepuasan pengunjung menjadi faktor penentu dari niat berkunjung kembali wisatawan, sedangkan variabel trust hanya sebagai pelengkap dan merupakan variabel moderasi yang bersifat lemah terhadap kepuasan pengunjung untuk menimbulkan niat berkunjung kembali di tengah pandemi COVID-19.

\section{SIMPULAN DAN SARAN}

\section{Simpulan}

Berdasarkan analisis yang dilakukan, atribut DTW agrowisata Taman Edelweis berpengaruh positif dan signifikan terhadap kepuasan pengunjung di tengah pandemi COVID-19. Pengunjung merasa puas khususnya pada keramahtamahan petani. Adapun atribut DTW berpengaruh positif dan signifikan terhadap niat berkunjung kembali wisatawan di tengah pandemi COVID-19. Kunjungan kembali sangat dipengaruhi oleh keramahtamahan petani. Begitupula kualitas pelayanan berpengaruh positif dan signifikan terhadap kepuasan pengunjung. Pengunjung merasa puas khususnya pada manajemen pengelola yang memperhatikan kesehatan pengunjung. Variabel kualitas layanan tidak berpengaruh signifikan terhadap niat berkunjung kembali wisatawan, dan hanya sebagai pelengkap dari atribut DTW untuk menimbulkan niat berkunjung kembali ke agrowisata Taman Edelweis di tengah pandemi COVID-19. Variabel kepuasan pengunjung berpengaruh positif dan signifikan terhadap niat berkunjung kembali. Namun, variabel trust hanya sebagai pelengkap dan merupakan variabel moderasi yang bersifat lemah terhadap kepuasan pengunjung untuk menimbulkan niat berkunjung kembali wisatawan di tengah pandemi COVID-19.

\section{Saran}

Saran yang dapat diberikan adalah pertama, pada atribut DTW yaitu terus berinovasi dalam pembuatan atraksi, penggunaan beberapa lahan milik warga sebagai penambahan fasilitas parkir, mempertahankan keramahtamahan, serta perbaikan akses jalan yang berlubang. Kedua, meningkatkan kualitas layanan, memperbaiki serta tetap melakukan perawatan terhadap fasilitas fisik. Ketiga, penambahan informasi mengenai tanaman padang kasna serta perawatan tanaman. Keempat, pembayaran tiket dalam satu kali pembayaran untuk meningkatkan rasa kenyamanan pengunjung, serta melakukan 
penelitian lebih lanjut seperti menganalisis pengaruh citra destinasi terhadap kepuasan dan niat berkunjung kembali wisatawan maupun penelitian lainnya.

\section{DAFTAR PUSTAKA}

Diarta, I. K. S. dan Sarjana, I. M. 2020. Pengaruh Atribut dan Kualitas Layanan terhadap Kepuasa Pengunjung Daya Tarik Wisata Pertanian Subak di Kota Denpasar Bali. Media Konservasi, 25(2)113-123.

Ghozali, I. 2014. Structural Equation Modeling Metode Alternative dengan Partial Least Squares (PLS). Semarang: Universitas Diponegoro.

Herman. 2018. "Pengaruh Atribut Destinasi terhadap Kepuasan Wisatawan dan Niat Berprilaku Wisatawan di Kota Makassar" (tesis). Denpasar: Universitas Udayana.

Jannah, R. N. 2020. "Pengaruh Motivasi terhadap Citra Destinasi dan Kepuasan Pengunjung Pantai Melasti Kabupaten Badung, Bali" (tesis). Denpasar: Universitas Udayana.

Kusyanda, M. R. P. 2019. "Pengaruh Atribut Destinasi Pariwisata dan Kualitas Pelayanan terhadap Kepuasan dan Niat Wisatawan Berkunjung Kembali di Pantai Melasti, Desa Ungasan, Kabupaten Badung" (tesis). Denpasar: Universitas Udayana.

Nantra. 2018. Akses Jalan ke Taman Edelweis Sempit. Nusa Bali, 28 Desember 2018, (serial online), [cited 2020 Oct. 16]. Available from: https://www.nusabali.com/berita /44188/akses-jalan-ke-taman-edelweis-sempit.

Pitana, I. G., dan Sarjana, I. M. 2020. Agrowisata Pariwisata Berbasis Pertanian. Singaraja: Mahima Institute Indonesia.

Prihadi, N. 2020. Peluang Pengembangan Wisata Alam Berkelanjutan Dalam Menghadapi Kenormalan Baru. Webinar Model Pengembangan dan Peluang Pembiayaan Agroekowisata Berkelanjutan di Indonesia. (serial online). Jul., [cited 2020 Jul. 20]. Available from: URL: https://bit.ly/MateriWebinar-20Juli.

Sholihin, M. dan Ratmono, D. 2013. Analisis SEM-PLS dengan WarpPLS 3.0 untuk Hubungan Nonlinier dalam Penelitian Sosial dan Bisnis. Yogyakarta: CV. Andi Offset.

Subekti, D. D. 2020. "Pengaruh Dimensi Customer Experience dan Kepercayaan terhadap Minat Berkunjung Kembali Pada Pengunjung Dira Kencong Jember" (skripsi). Jember: Universitas Jember. 